

Titulo do Trabalho

\title{
A IMPORTÂNCIA AMBIENTAL DOS PARQUES URBANOS E SUA CONTRIBUIÇÃO PARA A QUALIDADE DE VIDA DA POPULAÇÃO: UM FOCO NA SITUAÇÃO DOS PARQUES DE CUIABÁ - CUIABÁ/MT.
}

Nome do Autor (a) Principal

Jonatan Lucas da Conceição e Silva

Nome (s) do Coautor (a) (s)

André Luiz Santos Portela

Nome (s) do Orientador (a) (s)

Dr. Geraldo Antonio Gomes Almeida

Instituição ou Empresa

INSTITUTO FEDERAL DE EDUCAÇÃO, CIÊNCIA E TECNOLOGIA DE MATO GROSSO - CAMPUS CUIABÁ.

Instituição (s) de Fomento

PROPES - INSTITUTO FEDERAL DE EDUCAÇÃO, CIÊNCIA E TECNOLOGIA DE MATO GROSSO - CAMPUS CUIABÁ.

E-mail de contato

john_lucass@hotmail.com

Palavras-chave

Áreas verdes. Parques Urbanos. Parque Mãe Bonifácia. Qualidade de vida. 


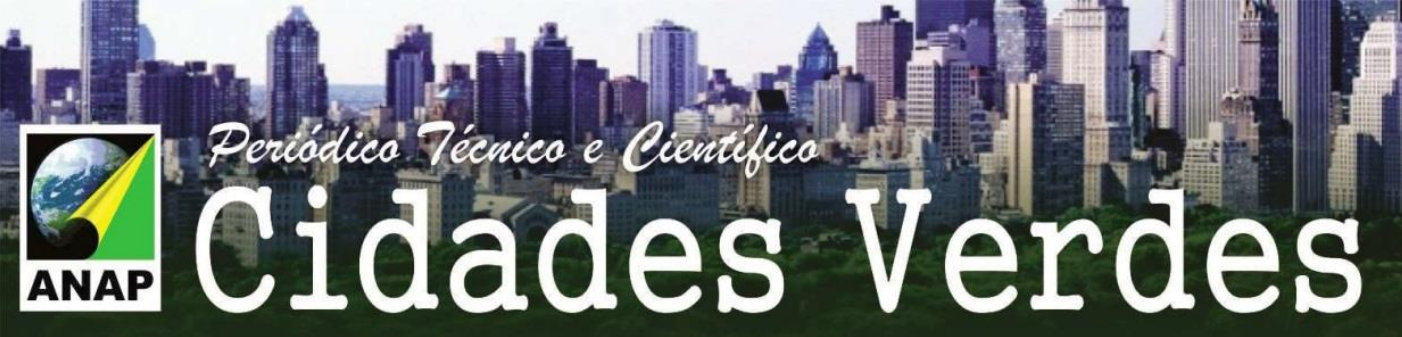

entornos, tem dados teóricos de natureza literal e é parte da fase de análise do método do SIDAD que orienta todo projeto da pesquisa, como pode ser visualizado na figura a seguir.

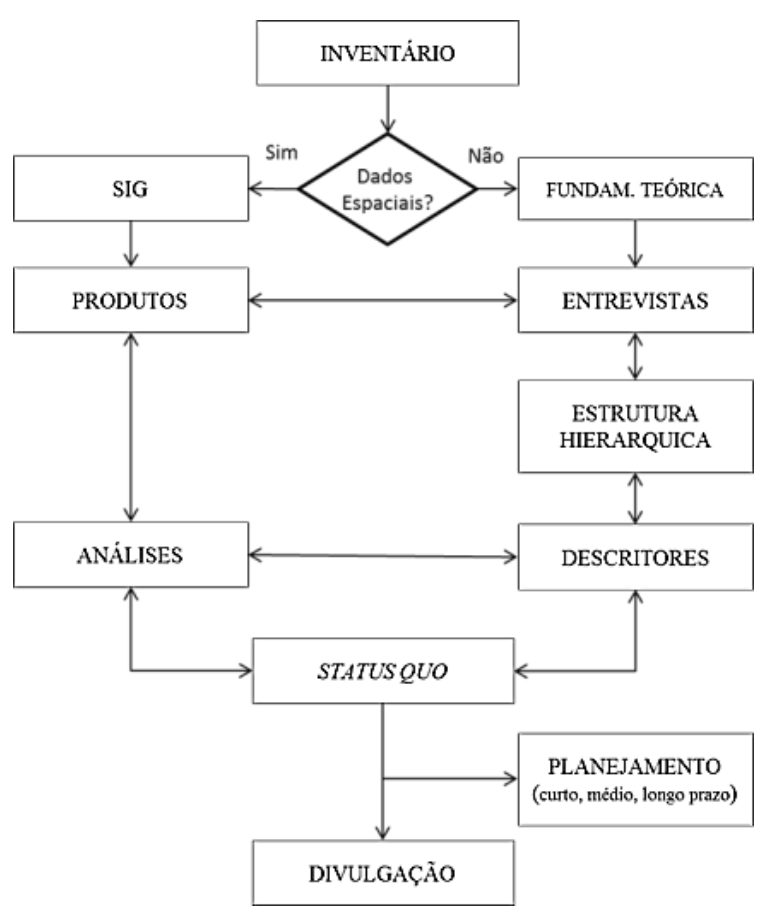

Fonte: Gomes Almeida, G. A. (2014).

\section{RESULTADOS E CONCLUSÃO}

\section{BREVE CONTEXTO ACERCA DAS PRINCIPAIS ÁREAS VERDES DE CUIABÁ}

As áreas verdes estão presentes numa enorme variedade de situações: em áreas públicas; em áreas de preservação permanente (APP); nos canteiros centrais; nas praças, parques, florestas e unidades de conservação (UC) urbanas; nos jardins institucionais; e nos terrenos públicos não edificados (MINISTÉRIO DO MEIO AMBIENTE, 2013). 


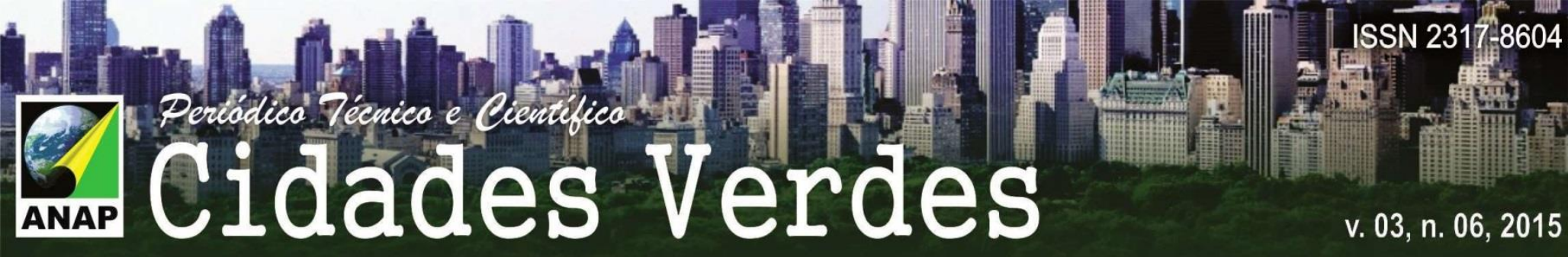

A cidade de Cuiabá, MT, que antigamente era conhecida por "Cidade Verde" pelos extensos fragmentos de cerrado presentes em toda área urbana da cidade cada vez mais vem sendo fragmentada pelos intensificação do crescimento urbano. A conservação das áreas florestadas dos Parques é de extrema importância, pois elas representam espécies da fauna do cerrado que necessitam de ambientes específicos. Além dos parques aqui selecionados, Cuiabá detém outras áreas verdes que aqui merecem ser elencadas como Parque Municipal Tia Nair, Parque Municipal Antônio Pires de Campos - Morro da Luz, Parque Municipal Memorial João Paulo II, Parque Federal da UFMT, Parque Zoobotânico da UFMT, Parque Jardim Zoobotânico, Horto Florestal Tote Garcia, Parque Municipal Lagoa Encantada, Parque Municipal Paiaguás ou Parque das Águas, Parque Municipal Dante de Oliveira, Parque Municipal Urbano Vila Militar, Parque Municipal Nossa Senhora Aparecida.

Por conta da extensão a ser tratada neste trabalho definiu-se analisar os três principais parques urbanos da cidade (conforme quadro 01 abaixo) e sua situação. A importância destes espaços é vital, principalmente no que diz respeito, a criação da consciência ambiental, para que futuras gerações possam desfrutar destas áreas urbanas tendo o mínimo contato com a natureza.

Quadro 1 - Apresentação dos parques selecionados para trabalho

\begin{tabular}{|l|l|l|}
\hline Area de Estudo & $\begin{array}{l}\text { Localização (região da } \\
\text { cidade) }\end{array}$ & Área \\
\hline Parque Estadual Mãe Bonifácia & Duque de Caxias (Oeste) & 77,16 há \\
\hline Parque Municipal Zé Bolo Flô & Coophema (Sul) & 53,75 há \\
\hline Parque Estadual Massairo Okamura & Morada do Ouro (Leste) & 66,40 há \\
\hline
\end{tabular}

Fonte: SEMA (2015).

Partindo de um modelo de desenvolvimento econômico vigente a onde 0 elemento paisagístico se torna mais atrativo que o funcional, o homem através da técnica ocupa e transforma o meio e produz ao longo dos anos a materialização que é a cidade ou espaço urbano, "As transformações na paisagem provocadas pelo 
surgimento e crescimento das cidades alteram o balanço de energia e o balanço hídrico urbano. Essas modificações são provocadas pela retirada da vegetação original, pelo aumento da circulação de veículos e pessoas, impermeabilização generalizada do solo, mudanças no relevo, concentração de edificações, canalização de córregos, além do lançamento de partículas e gases poluentes na atmosfera". (AMORIM, 2000, p.18). De acordo com Lefebvre (1991), a cidade nada mais é que a projeção da sociedade sobre um dado território, e que a mesma é moldada de acordo com os interesses da sociedade ali inserida, e, dos interesses do Estado constituído. Desta forma, as cidades estão em constantes mudanças de acordo com os interesses, crescem pelas ações e atividades diárias do homem, cada um com sua própria forma de apropriação, intervindo no espaço das mais variadas maneiras. A partir dessas intervenções na maioria do poder público, são apenas lançadas políticas sem os verdadeiros anseios funcionais que a população almeja, diante desta afirmação, segue abaixo quadro 02 abaixo, demonstrando alguns dos pontos encontrados na analise.

Quadro 2. Levantamento dos principais problemas dos seguintes parques de Cuiabá.

\begin{tabular}{|c|c|}
\hline Nome & Problemas \\
\hline $\begin{array}{l}\text { Parque Estadual Mãe } \\
\text { Bonifácia }\end{array}$ & $\begin{array}{l}\text { Mirante não funciona } \\
\text { Furtos dentro do parque } \\
\text { Criminosos usam o parque para se esconder } \\
\text { Atividades sexuais } \\
\text { Vandalismo nas entradas } \\
\text { Córrego Poluído } \\
\text { Falta de acessibilidade às pessoas carentes } \\
\text { Construções de alto impacto no entorno }\end{array}$ \\
\hline $\begin{array}{l}\text { Parque Estadual Zé Bolo Flô } \\
\text { (Parque da Saúde) }\end{array}$ & $\begin{array}{l}\text { Problemas de tratamento de efluentes } \\
\text { Falta de segurança para seus usuários } \\
\text { Depredação de aparelhos do parque }\end{array}$ \\
\hline $\begin{array}{l}\text { Parque Estadual Massairo } \\
\text { Okamura }\end{array}$ & $\begin{array}{l}\text { Local de problemas de segurança } \\
\text { Questões fundiárias } \\
\text { Casos de estupro } \\
\text { Falta de policiamento fixo } \\
\text { Furtos de casas próximos área de entorno } \\
\text { Degradação de APPs } \\
\text { Áreas de proteção pra evitar atropelamentos de animais } \\
\text { Pouca iluminação }\end{array}$ \\
\hline
\end{tabular}

Fonte: Elaboradores 


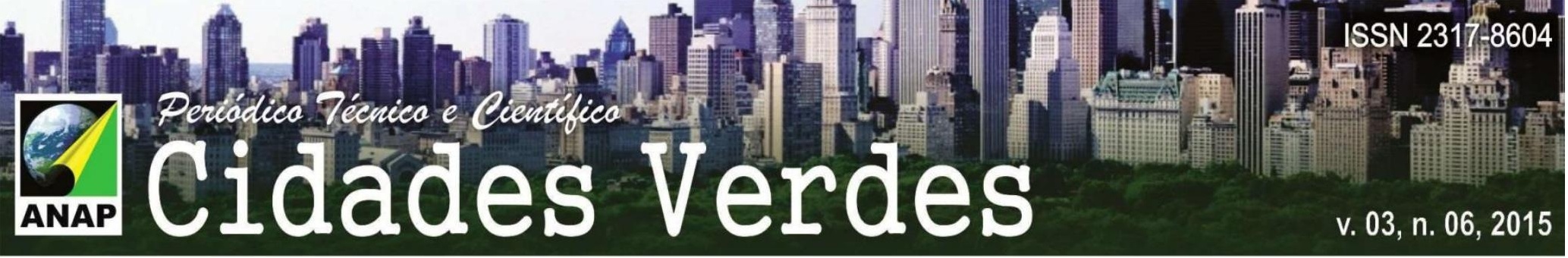

JEVINSKI. Neuza Cavalieri Rocha. Parque Mãe Bonifácia: um espaço de saber ambiental no contexto de uma área urbana protegida - Cuiabá, Mato Grosso. Dissertação apresentada ao Programa de Pós - Graduação em Educação. Instituto de Educação. Universidade Federal de Mato Grosso, 2009.

LEFEBVRE, Henri. O Direito à Cidade. Tradução de Rubens Eduardo Frias. Moraes: São Paulo. Ano 1991.

MINISTÉRIO DO MEIO AMBIENTE. Áreas verdes urbanas. Disponível em:

http://www.mma.gov.br/cidades-sustentaveis/areas-verdes-urbanas, acessado em: 20 de Maio de 2015.

SEMA - Secretaria de Estado de Meio Ambiente. Parque Estadual Mãe Bonifácia. Disponível em: http://www.sema.mt.gov.br/index.php?option=com_content\&view=article\&id=20\&ltemid=33; acessado em: 20 de Maio de 2015. 